\title{
Modulation by Insulin of the Co-localized LDL Receptor in Normal and Type-I Diabetic Subjects*
}

\author{
Shilpa Suneja ${ }^{1}$, Gopalakrishnan Ramakrishnan ${ }^{1}$, Nikhil Tandon ${ }^{2}$, Nimai Chand Chandra ${ }^{1 \#}$ \\ ${ }^{1}$ Department of Biochemistry, All India Institute of Medical Sciences, New Delhi, India; \\ ${ }^{2}$ Department of Endocrinology \& Metabolism, All India Institute of Medical Sciences, New Delhi, India. \\ Email: "nc1_chandra@hotmail.com
}

Received March $22^{\text {nd }}, 2011$; revised May $17^{\text {th }}, 2011$; accepted June $17^{\text {th }}, 2011$.

\begin{abstract}
Ongoing insulin therapy maintains LDL receptors at highly expressed state in Type-1 diabetic people; yet Type-1 diabetics are liable of having higher plasma LDL level. This disparity has raised doubt on the probability of existence of functionally active LDL receptor in such people. Confocal microscopy and immunoprecipitation have made it evident that a portion of insulin- and LDL receptors remain together in a co-localized mode, which only gets freed in presence of insulin. The findings of this study have shown that insulin therapy protects Type-1 diabetic people from the pathogenesis of atherosclerosis by decimating the inactivity of the co-localized LDL receptors in addition to its regular effect of having increased glucose tolerance. The existence of co-localized state of these two receptors and their dependence on insulin for independent activity has, at least, presented a reason for developing hypercholesterolemia and advanced coronary atherosclerotic lesion in chronic Type-1 diabetic subjects.
\end{abstract}

Keywords: LDL Receptor, Insulin Receptor, Type-1 Diabetes, Atherosclerosis, Insulin, LDL

\section{Introduction}

Atherosclerosis, a consequence of poor LDL receptor activity, is common in people with diabetes mellitus (DM) [1]. Hyperlipoproteinemia, resulting from chronic insulin-dependent diabetes mellitus (IDDM), may be reversible provided it is effectively treated with insulin. IDDM induced dyslipoproteinemia is not only a strong risk factor for the development of atherosclerosis; it is also one of the leading causes of specific microangiopathies [2,3]. Decreased LDL receptor sensitivity in DM patients hampers the treatment and promotes progression of diabetic microangiopathies [4]. Patients of type-2 DM (NIDDM), a defect of non-functionality of insulin, are also prone to altered blood lipid and lipoprotein profiles [5-14]. A study in Joslin clinic in Boston between 1956 and 1968 [15] showed that about 78\% of diabetic patients die from Coronary Artery Disease (CAD). Increased LDL level in blood is a well known high risk factor for CAD. As LDL-cholesterol is a major component of the atherosclerotic plaque, and since dia-

\footnotetext{
*S.S. was supported by a Scholarship Award from Indian Council of Medical Research (ICMR), India; G.R. was supported by a Senior Research Fellowship from the Council of Scientific and Industrial Research (CSIR), India.
}

betics (both type-1 and type-2) are prone to developing hypercholesterolemia; deficiency of insulin is expected to play some role in generating hypercholesterolemia in diabetic people. The increased transvascular LDL transport in patients with type-1 DM suggests lipoprotein influx into the arterial wall in people with type-1 DM, possibly explaining accelerated development of atherosclerosis in people of type-1 DM [16].

It is known that insulin increases the LDL receptor mRNA and receptor expression [17]. Although the exact mechanism is not known, the increased LDL receptor expression by added insulin, in an in vitro model experiment, has been found to be regulated by the known sterol regulated feedback mechanism in cells [18]. LDL receptor is considered as one of the major cell surface receptor protein responsible for plasma cholesterol clearance and maintenance of intracellular cholesterol homeostasis [19]. Although it is known that insulin cannot stimulate LDL receptor expression in sterol saturated cells [18], a consequence in atherosclerotic pathogenesis; no direct evidence, so far available, of the role of insulin in LDLR function in such cells. In diabetes mellitus the stimulatory effect of insulin on LDL receptor gene transcription is absent or meager [20]. However, 
it is not clear whether this is the only reason for decreased LDLR function in diabetes and its improvement with insulin administration.

Epidemiological studies show that in most of the Type-I Diabetes Mellitus have increased atherosclerosis and Type- 1 diabetes is a state of pancreatic insufficiency in insulin production. Since there is already a report on the profile of LDL receptor expression in Type-2 patients of DM [21]; an attempt has been made in this study to explore the possible mechanisms involved in poor LDLR function in patients of Type-I DM. We have studied the localization of two receptors, LDLR and IR (insulin receptor), by confocal microscopy in monocyte cells of normal human subjects and patients of Type-1 diabetes as well as in THP-1 cells. This shows that the two receptors normally exist in co-localized state in an un-stimulated situation. We have shown that insulin, either secreted after a meal or administered in Type-I diabetic subjects or even applied in the medium of THP-1 cells, disrupts their co-localized association. Uptake of LDL by monocytes is also increased in presence of insulin. Our results have shown that the existence of LDLR-IR co-localization and their dissociation by insulin is a regulatory mechanism in monitoring the LDL receptor function. The atherosclerotic complication in Type-I diabetes thus may be a consequence of lack of insulin to disrupt the co-localized state of LDLR-IR complex.

\section{Experimental Procedure}

\subsection{Materials and Reagents}

Lymphoprep ${ }^{\mathrm{TM}}$ was purchased from Axis. Shield Poe AS, Oslo, Norway. Antibodies against LDLR (goat polyclonal $\mathrm{IgG}$ ) and IR (rabbit polyclonal) as well as fluorescent antibodies, fluorescein isothiocyanate (FITC)-labeled goat anti-rabbit IgG for Insulin receptor and phycoerythrin(PE)-labeled rabbit antigoat IgG for LDLR, were purchased from Santa Cruz Biotechnology, Inc. California, USA (DAKOLSAB + Kit). Kits for cholesterol, HDL, LDL and Triglyceride estimation were obtained from Giess Diagnostic's snc, Via Crevinara, Rome, Italy. Kit for Glycated haemoglobin estimation was procured from from Life chem ${ }^{\mathrm{TM}} \mathrm{GHb}$, Kamineni Life Sciences Pvt.Ltd., Hyderabad. Kit for Glucose estimation was obtained from DiaSys Diagnostic Systems $\mathrm{GmbH}$, Holzheim, Alemania. Ethylene diamine tetra acetate (EDTA) as well as Antibiotic/Antifungal solution $(100 \times)$ was purchased from Sigma Chemical Co., St. Louis, MO, USA. RPMI-1640 powder was obtained from GIBCO BRL, Life Technologies, Inc. Grand Island, NY, USA. DAB Substrate Kit for Peroxidase and Streptavidin Peroxidase Kit were bought from Vector, Labo- ratories, Inc., Burlingame, CA, U.S.A. The Plasma for LDL extraction was obtained from the blood bank at All India Institute of Medical Sciences (AIIMS), New Delhi, India. All other chemicals used were of analytical reagent grade.

\subsection{Subjects}

Only male subjects ( $>20$ years, 15 control and 15 diabetic), control and treated Type- 1 diabetic, were included in the study following stipulated guidelines of the Ethical Clearance Committee of AIIMS, New Delhi, India.

\subsection{Sample Collection}

$10-12 \mathrm{ml}$ of blood samples were drawn aseptically from the superficial veins of each of the study subjects. Whole blood was used for monocyte isolation and estimation of glycosylated hemoglobin. Plasma was used for glucose estimation and serum was used for rest of the studies.

Plasma and serum was separated from whole blood by routine laboratory protocol.

\subsection{Blood Monocyte Isolation}

Blood monocytes were isolated according to the Company provided protocol (Sigma-Aldrich, Histopaque1077. Procedure No. 1077).

\subsection{Preparation of LDL from Human Blood Plasma}

LDL was collected from human blood plasma (obtained from the store of AIIMS Blood Bank hospital facility) by $\mathrm{NaCl}-\mathrm{KBr}$ density gradient ultracentrifugation according to Havel et al. [22]. The LDL density band was collected and dialysed against PBS (phosphate buffer saline, $\mathrm{pH} 7.2$ ) at $4^{\circ} \mathrm{C}$ for $24 \mathrm{~h}$ and total cholesterol was estimated as reported earlier [23].

\subsection{LDL Uptake Study by Blood Monocytes}

12-well plates were used for LDL uptake study. PBMC were isolated from fasting blood. Cells were counted in the Neubauer chamber and $2 \times 10^{5}$ cells were put in each well along with $1 \mathrm{ml}$ of RPMI medium containing antimycotic-antibiotic $(1 \times)$ (Sigma, USA) but no serum. Cells were incubated for one and half hour at $37^{\circ} \mathrm{C}$. Wells were then washed with the serum free RPMI media with antimycotic-antibiotic supplements. The cells were then incubated with different concentrations of LDL in serum free medium for $5 \mathrm{~h}$. After $5 \mathrm{~h}$, the leftover LDL concentration in the medium was measured to find the amount of LDL taken up the cells.

Standard curve was made for LDL uptake by monocytes from the control group's blood samples using 0,5 , 
$10,15,20,30,40,60$ and $80 \mu \mathrm{g}$ cholesterol $/ \mathrm{ml}$ culture medium. .

Four concentrations- $0,20,40$ and $80 \mu \mathrm{g}$ cholesterol $/ \mathrm{ml}$ were selected to compare the uptake pattern between diabetic and control subjects.

\subsection{Immunocytochemistry on Blood Monocytes}

Isolated monocytes were grown on cover slips in 12well plates and used for immunocytochemistry as described previously [23].

\subsection{Confocal Microscopy}

1) Human monocytes-Isolated monocytes from PBMC were grown on cover slips kept under RPMI-1640 within the wells of a 12-well plate. The cells grown on the cover slips were fixed in absolute acetone at $4^{\circ} \mathrm{C}$ for $10 \mathrm{~min}$. Cover slips were washed thrice with $0.01 \%$ Triton-X containing phosphate-buffer-saline (PBST) for 5 min each. Blocking was then carried out in $1 \%$ BSA at room temperature for $1 \mathrm{~h}$. The cells were then washed with PBST at room temperature. All cover slips were then incubated with one antibody, either LDLR [goat polyclonal (1:25)] or IR [rabbit polyclonal (1:25)] for 2 $\mathrm{h}$ at room temperature or overnight at $4{ }^{\circ} \mathrm{C}$ in a humid chamber. PBST wash was given. The steps henceforth were carried in dark. Fluorescent secondary antibody (antirabbit goat IgG-FITC diluted 1:50 for insulin receptor or antigoat rabbit IgG-PE diluted 1:50 for LDLR) was applied on cover slips and left for 1 hour incubation at room temperature. PBST wash was given as before. Incubation with second primary antibody on all the cover slips was done next and all the following steps described above were repeated again. The cover slips were mounted in glycerol: PBS: 1:1 and then visualized under confocal microscope. Image capturing was done within next $24 \mathrm{~h}$ on a Leica confocal microscope at the magnification of $400 \times$.

2) THP-1 cells-THP-1 cells were seeded onto 12 mm cover glasses in a 6 -well plate @ $5 \times 10^{5}$ cells/well and grown $24 \mathrm{~h}$ in 50nM PMA (required to induce cell adherence) containing RPMI-1640 medium supplemented with $10 \%$ fetal bovine serum and antibiotic-antimycotic mixture $(1 \times$ final concentration $)$ in presence of $95 \%$ air and $5 \% \mathrm{CO}_{2}$ at $37^{\circ} \mathrm{C}$. Following this the medium was removed and the cells were serum starved in the medium for $12 \mathrm{~h}$. After serum starvation, the medium was removed and the cells were washed with ice-cold PBS and then fixed in absolute acetone at $4^{\circ} \mathrm{C}$ and then again washed with PBS. Blocking was then carried out in $1 \%$ BSA at room temperature for 1 hour. Rest of the procedure was same as described with human monocytes above. The images were then captured within next $24 \mathrm{~h}$ on a Leica confocal microscope at the magnification of $400 \times$.

For insulin treatment, the serum starved cells were placed in $2 \mathrm{ml}$ of ice-cold medium containing $15 \mu \mathrm{g} / \mathrm{ml}$ insulin and incubated at $4^{\circ} \mathrm{C}$ for $1 \mathrm{~h}$. Following this, the medium was replaced with fresh medium at $37^{\circ} \mathrm{C}$ and incubated for $10 \mathrm{~min}$.

\subsection{Estimation of Glucose, Total Cholesterol, HDL, LDL, Triglyceride and Glycosylated Hemoglobin}

Respective Kits were used to estimate concentrations of glucose, total cholesterol, HDL, LDL and triglyceride in plasma/serum isolated from fasting male subjects. The glycosylated hemoglobin was estimated in the whole blood from same fasting male subjects.

Kit for Glucose estimation was from DiaSys Diagnostic Systems GmbH, Holzheim, Germany.

Kits for Cholesterol, HDL, LDL and Triglyceride estimation were from Giess Diagnostics Inc, Via Crevinara, Rome, Italy.

Kits for Glycosylated haemoglobin estimation was from Life $\mathrm{Chem}^{\mathrm{TM}} \mathrm{GHb}$, Kamineni Life Sciences Pvt.Ltd., Hyderabad, India.

\subsection{Estimation of Insulin and C-Peptide}

Insulin and C-peptide levels in serum were estimated from the facility of the Department of Endocrinology and Metabolism, AIIMS, New Delhi, India. In brief, C-peptide was done by an immunoassay format and insulin estimation was carried out following an immunometric format on an ELECSYS 2010 auto-analyzer (ROCHE) using an electrochemiluminiscence assay. Minimum detectability for C-peptide was $0.01 \mathrm{ng} / \mathrm{ml}$ and for insulin was $0.2 \mu \mathrm{U} / \mathrm{ml}$.

\subsection{THP-1 Cell Culture}

Cells were grown to approximately $90 \%$ confluence in RPMI-1640 medium supplemented with $10 \%$ fetal bovine serum and antibiotic-antimycotic mixture $(1 \times$ final concentration) (Sigma, USA) in presence of $95 \%$ air and $5 \% \mathrm{CO}_{2}$ in a $37^{\circ} \mathrm{C}$ incubator. The medium was removed and cells were grown in serum deficient medium for another $12 \mathrm{~h}$ to stimulate receptor protein expression. The cells were then used to prepare cell lysate by incubating in cell lysis buffer, containing $50 \mathrm{mM}$ Tris- $\mathrm{HCl}$ (pH 7.6), $300 \mathrm{mM} \mathrm{NaCl}, 0.5 \%$ Triton-X-100, $5 \mathrm{mM}$ EDTA with $2 \mathrm{mM}$ PMSF and $10 \mathrm{U} / \mathrm{ml}$ aprotinin added just before use by vortexing strongly till the consistency of the solution was changed. This lysed suspension was kept on ice for $30 \mathrm{~min}$ and then spun at $10,000 \mathrm{~g}$ for 15 $\min$ at $4^{\circ} \mathrm{C}$. The supernatant was collected and protein content was estimated. 


\subsection{Immunoprecipitation}

THP-1 cell lysate containing $100 \mu \mathrm{g}$ protein was mixed with the anti-LDLR antibody (anti-human goat polyclonal, sc-11822 (N-17), Santa Cruz biotechnology, Inc. USA) and incubated overnight at $4{ }^{\circ} \mathrm{C}$. Protein A agarose beads was blocked with $4 \%$ BSA for $2 \mathrm{~h}$ separately at $4^{\circ} \mathrm{C}$ and then washed thrice with PBST. These blocked beads were then added to the lysate antibody mixture and kept at $4{ }^{\circ} \mathrm{C}$ for $2 \mathrm{~h}$ with constant mixing every 15 20 minutes. The beads were then collected by centrifugation at $8000 \times \mathrm{g}$ for 5 minutes at $4^{\circ} \mathrm{C}$ and washed with chilled PBST. They were then re-suspended in protein loading buffer and boiled for 5 minutes. The beads were then pelleted by centrifugation and the supernatant was used for SDS-PAGE.

\subsection{Western Blotting/Immunoblot}

The protein(s) from SDS-PAGE was transferred onto a nitrocellulose membrane and developed with anti-human-insulin receptor $\beta$ chain rabbit polyclonal antibody (sc-711 (C-19), santa cruz biotechnology, Inc. USA) diluted 1:8000 as reported previously [23].

\subsection{Protein Estimation}

Protein estimation was according to the method of Bradford et al. using bovine serum albumin as the standard [24].

\subsection{Statistics}

Standard diviation was calculated and student's t-test was used to compare the means of two treatments. The probability factor to judge the significance of the difference between the two means is shown as $p$ value in the parenthesis.

\section{Results}

\subsection{Biochemical Parameters}

Male subjects, normal and Type- 1 diabetic, between 20 to 50 years of age were included in this study. Since estrogen influences lipoprotein metabolism in females, only male subjects were considered in this study. On an average, the blood pressure, body weight and body mass index (BMI) of the subjects (not shown) in our study were maintained within limits to exclude the possibilities of the mixed effects expected from other atherosclerotic inducers like hypertension, over-weight or obesity. The biochemical parameters (Table 1) in this study had made it evident that the subjects with a very high plasma glucose (fasting concentration shown) and glycated hemoglobin also had higher values in atherogenic index $[\log (\mathrm{TG} / \mathrm{HDL} C \mathrm{C})]$, triglycerides (TG) and low density lipoprotein (LDL) concentrations, which all are
Table 1. Biochemical parameters in Controls and Type-1 DM subjects. Atherogenic index $\left[\log \left(\mathrm{TG} / \mathrm{HDL} \_\mathrm{C}\right)\right]$ was found considerably high in Type-1 diabetic subjects in addition to high plasma glucose and glycosylated Hb. LDLcholesterol and triglyceride concentrations were also found noticeably high in diabetic patients as compared to the control group.

\begin{tabular}{llllll}
\hline PARAMETERS & NORMAL & \multicolumn{2}{l}{ NO.OF } & CONTROL & DIABETIC \\
& RANGE & \multicolumn{2}{l}{ SUBJECTS } & SUBJECTS & SUBJECTS \\
& & CS & DS & & \\
\hline 1. PLASMA & $70-110$ & 15 & 15 & 78.85 & 241.03 \\
GLUCOSE(F) & $\mathrm{mg} / \mathrm{dl}$ & & & \pm 3.92 & \pm 62.96 \\
2. GLY. Hb. & $3 \%-5 \%$ & 15 & 15 & 4.07 & 10.34 \\
& & & & \pm 0.63 & \pm 3.6 \\
3. TOTAL CHO- & $<200$ & 15 & 15 & 141 & 178.86 \\
LESTEROL & $\mathrm{mg} / \mathrm{dl}$ & & & \pm 25.57 & \pm 15.06 \\
4. LDL- & $66-178$ & 15 & 15 & 93.84 & 114.28 \\
CHOLESTEROL & $\mathrm{mg} / \mathrm{dl}$ & & & \pm 20.23 & \pm 34.06 \\
5. HDL- & $30-35$ & 15 & 15 & 34.05 & 36.39 \\
CHOLESTEROL & $\mathrm{mg} / \mathrm{dl}$ & & & \pm 4.93 & \pm 1.96 \\
6. LDL/HDL & $2-4$ & 15 & 15 & 3.05 & 3.95 \\
& & & & \pm 1.19 & \pm 1.5 \\
7.ATHEROGENIC & $<0.5$ & 15 & 15 & 0.299 & 0.852 \\
INDEX & & & & \pm 0.012 & \pm 0.024 \\
[log(TG/HDL_C)] & & & & & \\
8.TGs & $36-115$ & 15 & 15 & 83.47 & 119.31 \\
(Triglycerides) & $\mathrm{mg} / \mathrm{dl}$ & & & \pm 23.40 & \pm 17.68 \\
9.LDL/TG & $1.4-1.6$ & \multirow{2}{*}{15} & 15 & 1.26 & 1.88 \\
& & & & \pm 0.95 & \pm 0.94 \\
\hline
\end{tabular}

known risk factors to escalate atherosclerotic propensity of an individual in course of time. Thus it was reflected from the blood chemistry that subjects of Type-1 DM had a high level of blood glucose accompanied by dyslipidemia.

\subsection{Receptor Expression}

Immunocytochemistry was performed with monocytes from fasting human plasma using respective antibodies to evaluate the extent of expressions of insulin receptor (IR) and LDL receptor (LDLR) in insulin treated Type-1 diabetic subjects (Figures 1(a) and (b)). Receptor expressions were judged in fifteen Type- 1 diabetic subjects against the expression profile of fifteen normal subjects. Extent of receptor expression was estimated by integral optical density (IOD) of the DAB stained receptors. The graphical representation of the IOD of stained receptors (Figure 1(c)) provided a direct comparison of the expression profile of IR and LDLR between Type-1 diabetic and control subjects. It was apparent from Figure 1(c) that both the receptor expressions (IR and LDLR) were maintained at a higher level in insulin treated Type-1 diabetic subjects as compared to the controls. It was an interesting observation that in spite of having high LDLR expression, the Type-1 diabetics were still exhibiting a higher atherogenic index (Table 1). 
Insulin receptor expression

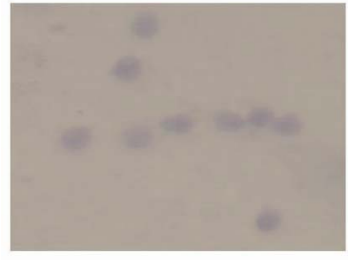

CONTROL

LDL receptor expression

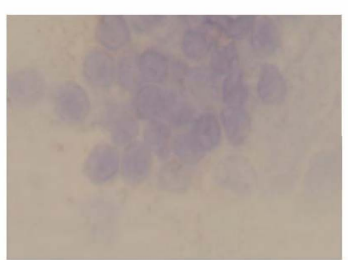

CONTROL

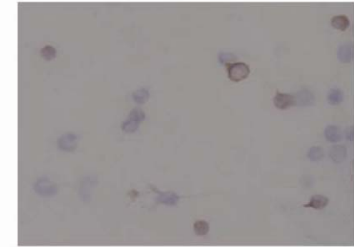

DIABETES MELLITUS (a)

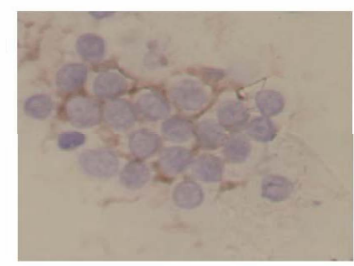

DIABETES MELLITUS

(b)

RECEPTOR EXPRESSION

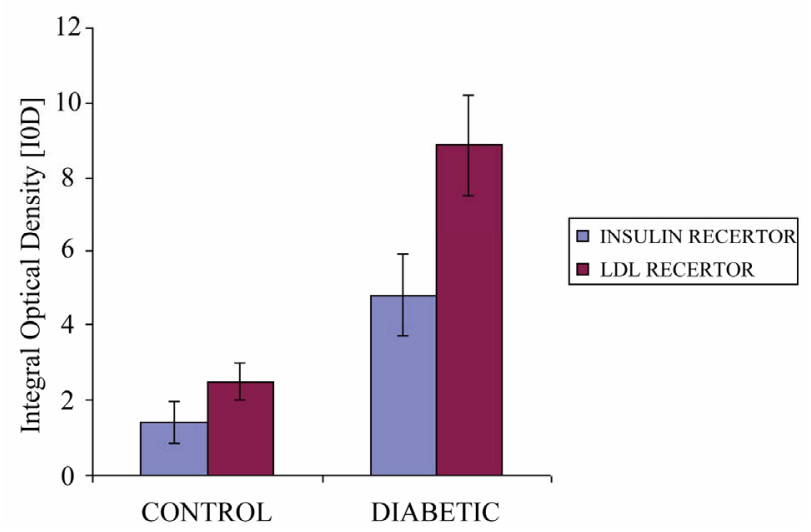

(c)

Figure 1. The Figures (a) and (b) represent receptor expression of IR and LDLR in control and diabetic groups respectively. The variations of IR \& LDLR expression among subjects of two groups (control/diabetic) have been evaluated by estimating Integral Optical Density (IOD) of expressions (shown by bar graph in panel-c).

\subsection{Functional Activity of LDLR}

The LDL uptake profile of the expressed LDL receptors on the surface of fasting human plasma monocytes, in control and diabetic subjects, are shown in Figure 2.

The graphical representation in Figure 2(a) has shown the LDL-cholesterol concentration taken up by a population of monocytes isolated from $2 \times 10^{5} \mathrm{PBMC}$ of control fasting subjects. It increased almost linearly in a rate controlled manner with the increased availability of LDL-cholesterol till $30 \mu \mathrm{g} / \mathrm{ml} \mathrm{LDL}$ cholesterol in the culture medium (X-axis). Beyond $30 \mu \mathrm{g} / \mathrm{ml}$ LDL the linearity discontinued but, uptake of LDL continued till a concentration of $80 \mu \mathrm{g} / \mathrm{ml}$ LDL-cholesterol added in the medium. When the monocytes were exposed to LDL concentration beyond $80 \mu \mathrm{g} / \mathrm{ml}$, they burst and showed characteristics of foam cells (Figures 2(c)-(e) show incubation with LDL up to $100 \mu \mathrm{g} / \mathrm{ml}$ medium of the monocytes isolated from control subjects).

In Figure 2(b) LDL-cholesterol uptake by plasma monocytes has been compared between control and diabetic people. PBMC(s) were collected from fasting individuals only. Since sufficient blood samples were hardly available from sick patients to study all nine concentrations as tested in the samples from control subjects, only four selected concentrations $(0,20,40$ and $80 \mu \mathrm{g} / \mathrm{ml}$ medium) were chosen for this study to compare the uptake rate of LDL-cholesterol between normal and diabetic subjects. Like control subjects, the uptake initially increased in diabetic group in a linear fashion till a concentration of $30 \mu \mathrm{g} / \mathrm{ml}$ of LDL cholesterol in the medium followed by a slower phase till a saturation of $80 \mu \mathrm{g} / \mathrm{ml} \mathrm{LDL}-$ cholesterol concentration in the culture medium. However, at each point the uptake by diabetic subjects was less than that of controls $\left(p_{40(\mathrm{~S} 1, \mathrm{~S} 2)}<0.05\right.$, $\left.p_{80(\mathrm{~S} 1, \mathrm{~S} 2)}<0.01\right)$. This low LDL receptor activity gave a contrast impact to the highly expressed LDL receptors in the diabetic subjects.

\subsection{Co-localization Studies}

\section{Co-Immuno-Precipitation}

LDL receptors were immunoprecipitated from the cell lysate prepared from THP-1 cells incubated with and without insulin. The immune-precipitate was probed with anti-insulin-receptor- $\beta$-chain antibody after bloting on nitro cellulose membrane (Figure 3(a)). The insulin receptor band was absent in the insulin treated lane on the nitrocellulose membrane (but present in the lane with no insulin) after development with enhanced chemiluminisence (Santa Cruz Biotechnology, USA). This showed that in absence of insulin the two receptors co-immunoprecipitated but, insulin treatment separates them apart and hence no band of insulin receptor (IR) was found on nitrocellulose membrane because IR was not co-immunoprecipitated with LDLR.

\subsection{Confocal Microscopy}

Confocal microscopy (Figure 3(b)) of the two receptors (IR and LDLR) and their super imposition by computer software made it apparent that the two receptors existed in both free (red and green) and co-localized state (yellow) in monocytes isolated from fasting human blood of normal subjects of varying age groups. The extent of co-localization varied between individuals, irrespective of age. More co-localization was expected to be a repre- 


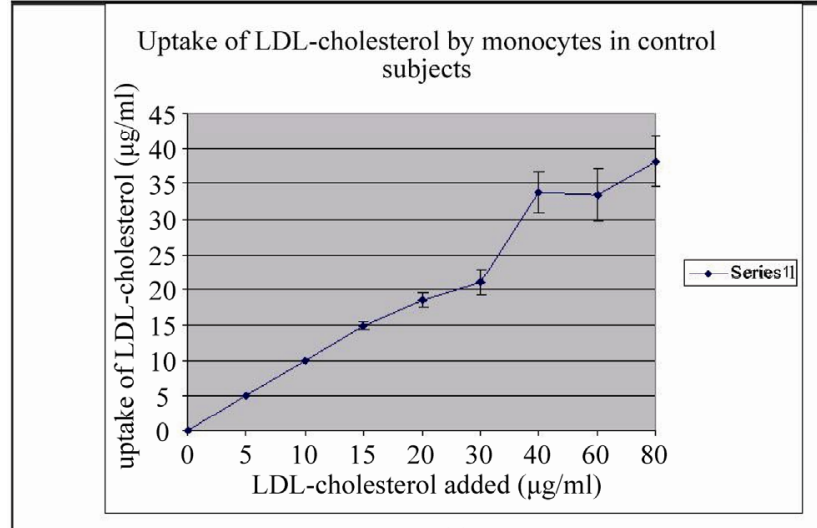

(a)

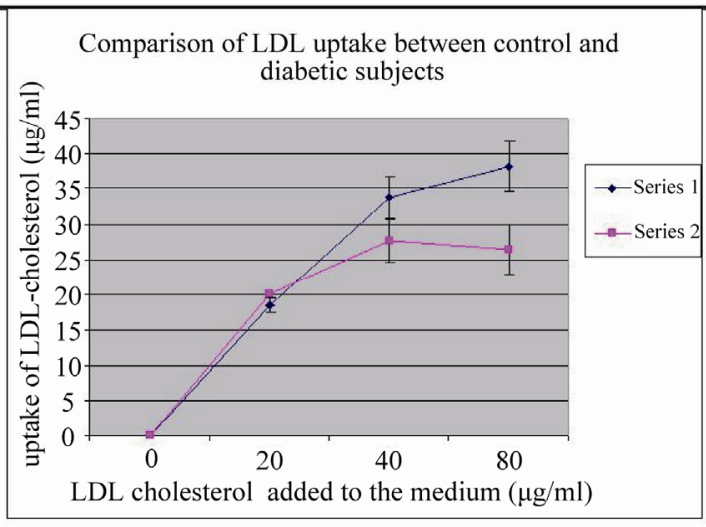

(b)

Series 1: Control subjects. Series 2: Diabetic subjects. Cell population: Monocytes from PBMC $\left(2 \times 10^{5}\right.$ cells $)$

Changing of density of Monocytes after $2 \mathrm{~h}$ incubation with various LDL concentrations in the medium

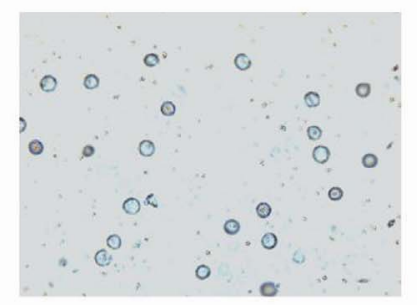

$0 \mu \mathrm{g} / \mathrm{ml} \mathrm{LDL}$

(c)

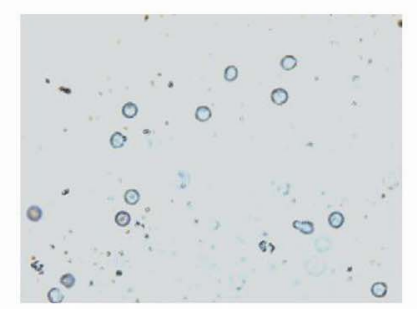

$50 \mu \mathrm{g} / \mathrm{ml} \mathrm{LDL}$

(d)

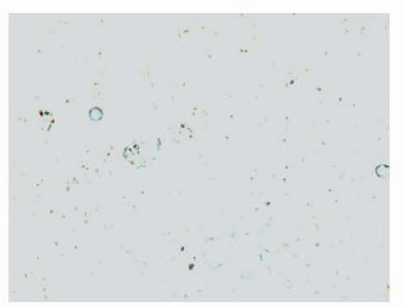

$100 \mu \mathrm{g} / \mathrm{ml} \mathrm{LDL}$

(e)

Monocytes were ruptured at $100 \mu \mathrm{g} / \mathrm{ml} \mathrm{LDL}$ in the medium (samples collects from control subjects)

Figure 2. Panel-(a) (figure): The figure shows the uptake of LDL-cholesterol by monocytes in control subjects. Panel-(b) (figure): The figure shows the comparison of LDL-cholesterol uptake between normal subjects and diabetic patients. The figures in Panel-(c), (d) and (e) show the comparison of monocytic cell (isolated from control subjects) lysis with increasing concentration of LDL in the medium.

sentative of more inactive LDL receptors because co-localized LDL receptors may exist in a less active form. The processing protocol of cells for the confocal microscopy had detergents $(0.01 \%$ triton-X-100) to stop nonspecific interactions on the cell surface by the components of assay system. The permeabilization of plasma membrane by detergent allowed antibodies to stain intracellular receptors. Besides plasma membrane, the evidence of colocalization was also seen in cytoplasm.

\subsection{In-Vitro Model Study}

Monocytes were isolated (see methods) from diabetic subjects and the cultured monocyte cells were treated with and without $15 \mu \mathrm{g}$ of insulin/ml (concentration found suitable for moderate LDL uptake in similar experiments not shown here) culture medium for $10 \mathrm{~min}$ utes. The control cells (from diabetic subject and insulin untreated) and insulin treated cells were processed for confocal microscopy to see the effect of insulin on receptor colocalization. This experiment also showed the separation of colocalized receptors by insulin (Figure 3(c)). When the experiment was repeated with THP-1 monocyte cells cultured in the laboratory, the same result was replicated (Figure 3(d)).

\subsection{Non-Hyperglycemic Control Subjects}

The extent of co-localization of IR and LDLR was studied in normal subjects (Figure 4), having no symptom of hyperglycemia and without any family history of diabetes, before and after of oral glucose administration. It was expected that oral glucose would induce insulin secretion resulting in reduction of co-localization of the receptors. The plasma level of glucose, glycated-Hb $\left(\mathrm{Hb}-\mathrm{A}_{1 \mathrm{c}}\right)$ and cholesterol were within normal limits in 


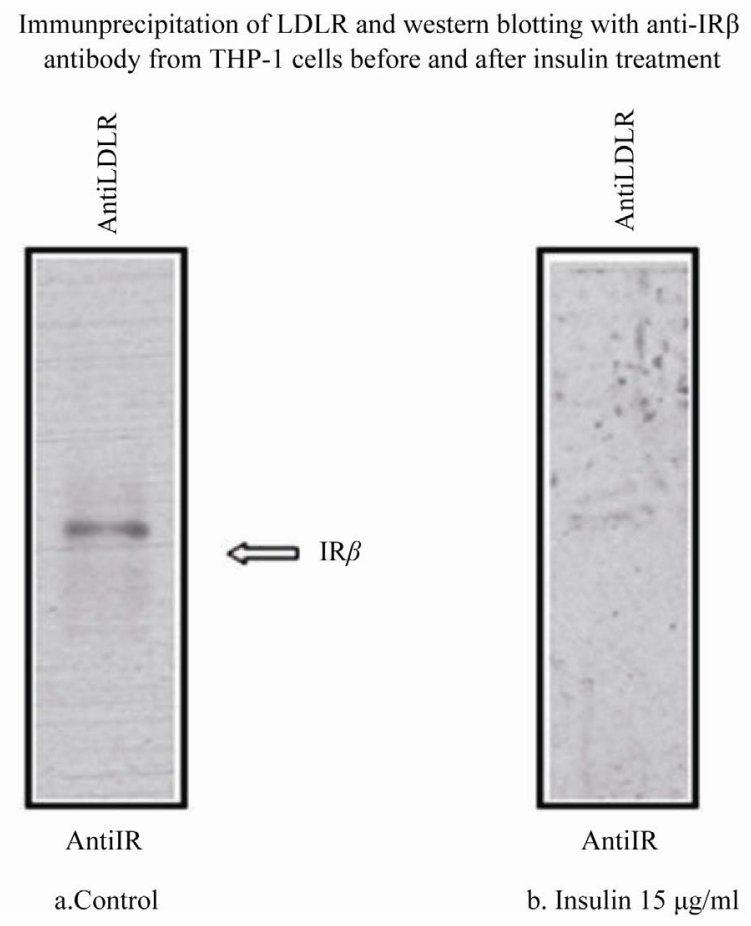

(a)

Confocal microscopy of monocytes isolated from fasting human blood for insulin and LDL receptors. (all pictures taken at magnification of $400 \mathrm{X}$ )

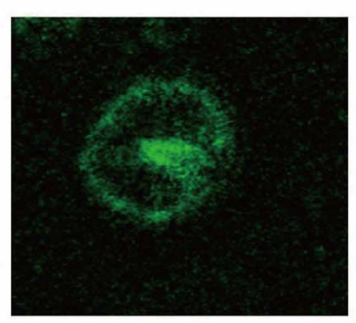

Insulin receptor

(FITC)

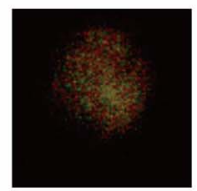

20 years

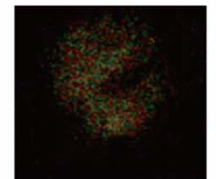

30 years

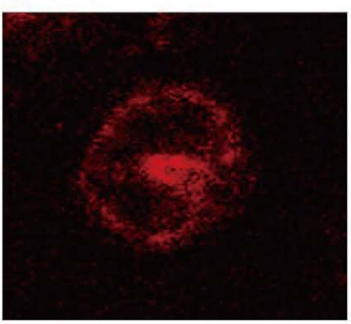

$\mathrm{LDL}$ receptor $(\mathrm{PE})$

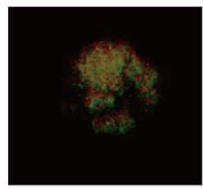

40 years

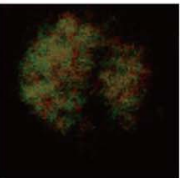

50 years

(b)

Role of insulin on co-localized receptor complex in human monocytes

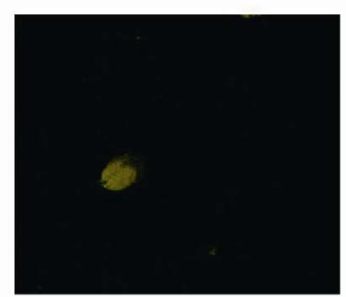

Diabctic control

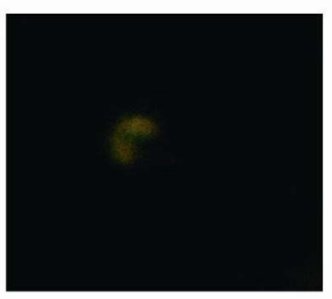

$15 \mu \mathrm{g} / \mathrm{ml}$ Insulin

(c) 
Role of insulin on co-localized receptor complex in cultured THP-1 cells

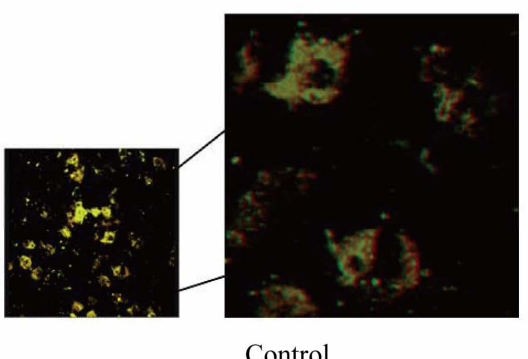

Control

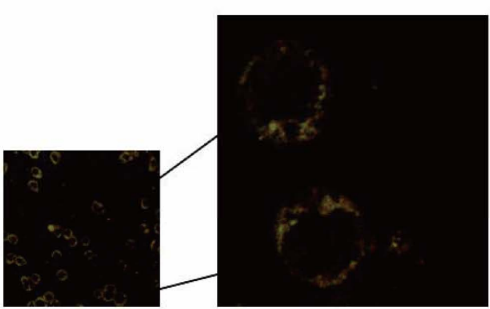

$15 \mu \mathrm{g} / \mathrm{ml}$ Insulin

(d)

Figure 3. (a): LDL receptor was immunoprecipitated by anti-LDLR antibody from THP-1 cells treated with and without insulin $(15 \mu \mathrm{g} / \mathrm{ml})$. After running on PAGE, the precipitate(s) was transferred on nitrocellulose membrane and treated with anti-insulin receptor antibody. After development by enhanced chemi-luminisence (Santa Cruz Biotechnology, USA), an insulin receptor band was found only in control panel.

all three volunteers participated in this study (Figure 4(d)). All three subjects showed normal GTT (glucose tolerance test) (Figures 4 (a)-(c)). At 0.5 h, there was an increased concentration of insulin in response to the glucose consumed by these subjects after donating their fasting blood. The changes of glucose and insulin concentration after each $0.5 \mathrm{~h}$ were the characteristics of the individual's own metabolic activity. The C-peptide level remained constant from $0.5 \mathrm{~h}$ onwards indicating that no further insulin was secreted after $0.5 \mathrm{hr}$. The co-localized state of the two receptors (LDLR and IR) in each subject was found inversely co-related with the plasma insulin level following glucose ingestion. A maximum separation of the two receptors from their co-localized state (Figures 4 (a)-(c), confocal pictures) was found at $0.5 \mathrm{~h}$ when insulin concentration was at its maximal height. The next 2hs follow up [Fasting and post glucose diet] showed that the co-localized state of the two receptors increased as the plasma insulin levels reduced. At $2 \mathrm{~h}$, the co-localized state of the receptors was close to the fasting pattern. Because of experimental compliance, the last $2 \mathrm{hr}$ data point of the Subject-2 [C-2] is not available. Hence, this co-relation study supports the role of insulin in generating free LDLR from the IR-LDLR co-localized complex.

\subsection{Diabetic Subjects}

The co-localization of IR and LDLR was also studied in three diabetic subjects after administering insulin. The plasma level of glucose and glycated- $\mathrm{Hb}\left(\mathrm{Hb}-\mathrm{A}_{1 \mathrm{c}}\right)$ were noticeably high in all three subjects (Figure 5(d)). Subjects DM-1 and DM-3 could maintain the normal limits of total and LDL cholesterol. Subject DM-2 had a markedly high value for both. Since a complete GTT was unsuitable for these diabetic subjects, only three time point were studied. The samples were taken: I) at fasting state, II) half an hour after a meal taken and half an hour after of insulin injection and III) immediately before next insulin injection (about $4 \mathrm{~h}$ after the second bleed). Since Type-1 diabetic people were deficient in their in vivo insulin, the stability of the colocalized receptors was judged against the persistance of externally added insulin in the blood plasma. The profile of all the three parameters viz glucose, insulin and C-peptide in blood plasma have been compared with the confocal representation of IR-LDLR colocalized complex for each diabetic subject (Figures 5(a)-(c), DM-1, DM-2 and DM-3). The Subject DM-1 showed that the co-localized receptors in the fasting monocytes got separated and became free after administration of external Insulin which led to a fall in plasma glucose. The initial extent of co-localization of DM-2 and DM-3 was less than that of DM-1, probably because of the administration of intermediate long acting insulin at night. However, even in these subjects the administration of soluble insulin resulted in a marked decrease in co-localization of the receptors as reflected in the second sample (i.e. one hr after insulin injection and meal). Co-localization was restored in the third sample taken 4 $\mathrm{h}$ later. This again showed that Insulin was responsible for generating free receptors from the co-localized IR-LDLR complex.

In Subject DM-3 the rate of fall was relatively slow for insulin; the IR and LDLR also existed even longer in free non-colocalized fashion.

\section{Discussion}

Type-1 diabetic patients are at increased risk of atherosclerosis and its clinical sequel. Retention of lipoproteins $[25,26]$ in the arterial wall initiates the early stage of atherosclerosis. This is then followed by activation of endothelial expression of adhesion molecules [27-29], development of cholesterol-laden foam cells [30,31] and formation of atherosclerotic plaque [32-34]. The gly- 
SUBJECT-1 [C-1]

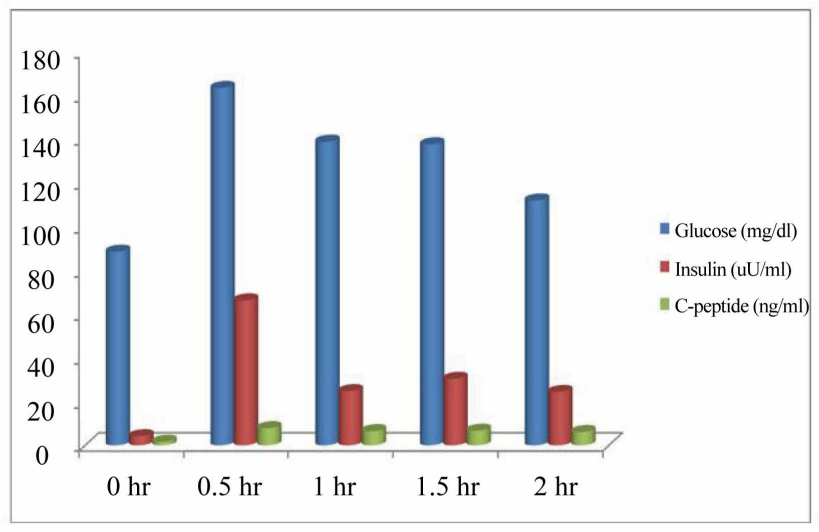

$1: 0 \mathrm{hr} \quad 2: 0.5 \mathrm{hr} \quad 3: 1 \mathrm{hr} \quad 4: 1.5 \mathrm{hr}$

$1.5 \mathrm{~h}$

$2 \mathrm{~h}$
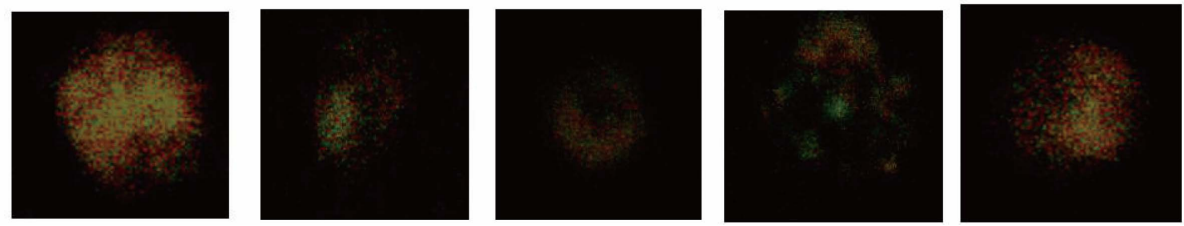

(a)

SUBJECT-2 [C-2]

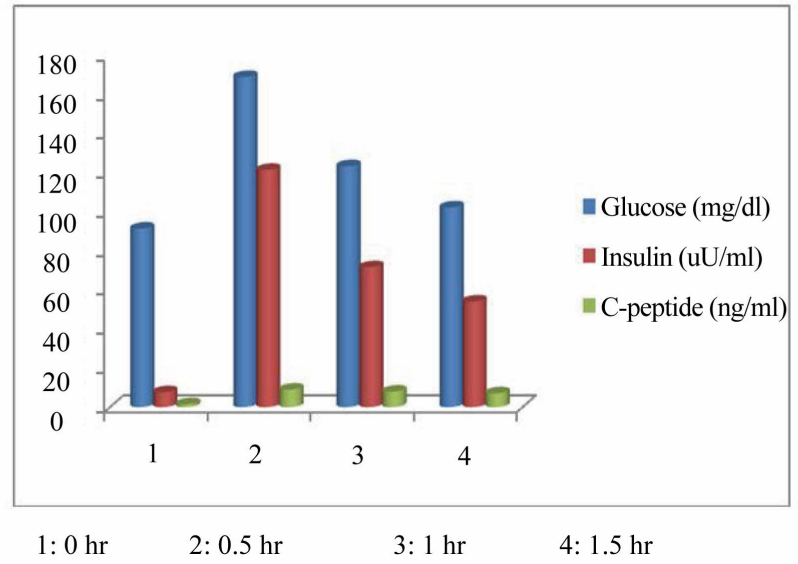

Fasting: $\mathrm{O} h$

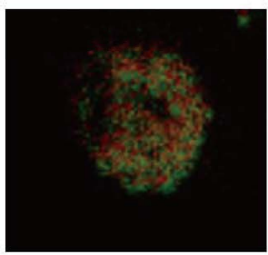

$0.5 \mathrm{~h}$

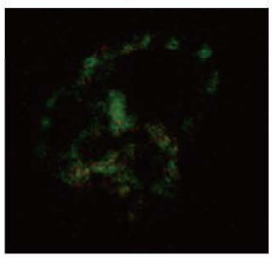

$1 \mathrm{~h}$

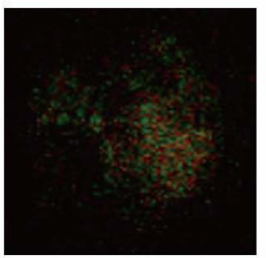

(b)
$1.5 \mathrm{~h}$

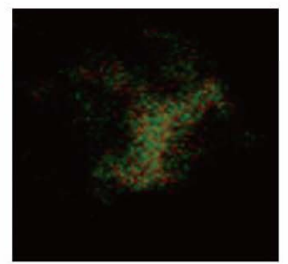




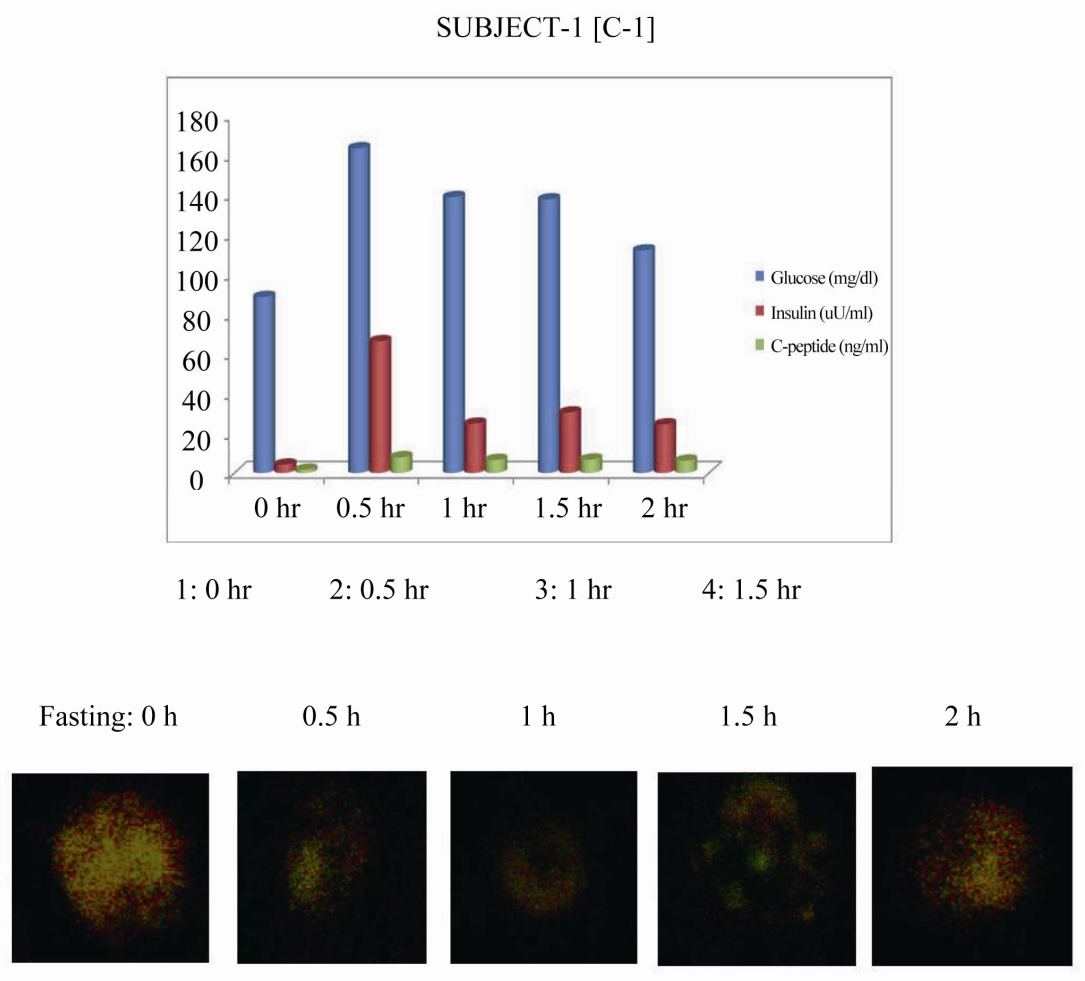

(c)

Biochemical parameters

\begin{tabular}{|l|l|l|l|}
\hline PARAMETERS ( in fasting) & $\mathrm{C}-1$ & $\mathrm{C}-2$ & $\mathrm{C}-3$ \\
\hline PLASMA GLUCOSE (mg/dl) & 88.57 & 91.43 & 80.66 \\
\hline Gly-Hb(\%) & 3.5 & 3.6 & 3.2 \\
\hline TOTAL CHOLESTEROL (mg/dl) & 118 & 170 & 131 \\
\hline LDL- CHOLESTEROL (mg/dl) & 27.12 & 118.5 & 39.66 \\
\hline
\end{tabular}

(d)

Figure 4. The colocalization pattern of two receptors, LDL receptor and insulin receptor, were compared in three control subjects with their blood glucose, insulin and C-peptide levels in fasting and prospandial state. The biochemical parameters assayed in the fasting blood of those three controls are depicted in associated table.

cated lipoprotein(s) affects LDL receptor activity. Epidemiological data has firmly established the correlation between diabetes and atherosclerosis. The present study intends to find the possible reason(s) for developing atherosclerosis in the people of Type-1 diabetes by studying the inter-relation, if any, between insulin, insulin receptor (IR)and LDL receptor (LDLR) in a model system with peripheral blood mononuclear cells (PBMC) isolated from Type-1 diabetic subjects and their age matched controls.

Keeping in mind that LDL receptor function is compromised in DM, the present study tried to elucidate the inter relationship between insulin activity and the ob- served co-localization of IR and LDLR in normal and diabetic subjects. The THP-1 monocyte cell line was also used to verify the effect of insulin on the aggregation of two receptors in (IR and LDLR) in vitro studies. Type-I diabetes was studied because the effects of absolute insulin deficiency and its replenishment was easier to determine. Only male subjects were included, so as to rule out the confounding effects of estrogens. The routine therapeutic protocol of the Type-1 diabetic subjects was not interrupted by any occasion of the present study. In fact, the two groups (control and treated diabetic) were found comparable except in terms of glycosylated hemoglobin and lipid profiles (Table 1). We observed 
Comprison of Glucose, Insulin and C-peptide concentrations in diabetic patients with confocal representation of their Insulin and LDL receptors

PATIENT-1 [DM-1]

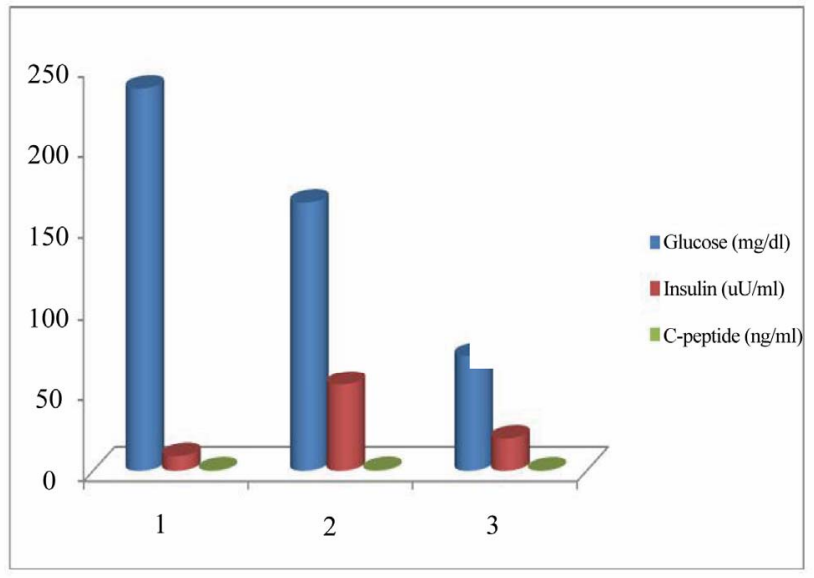

1
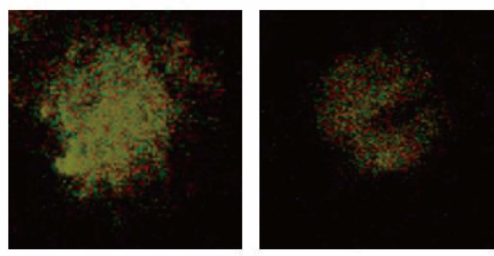

(a)

Comprison of Glucose, Insulin and C-peptide concentrations in diabetic patients with confocal representation of their Insulin and LDL receptors

PATIENT-2 [DM-2]

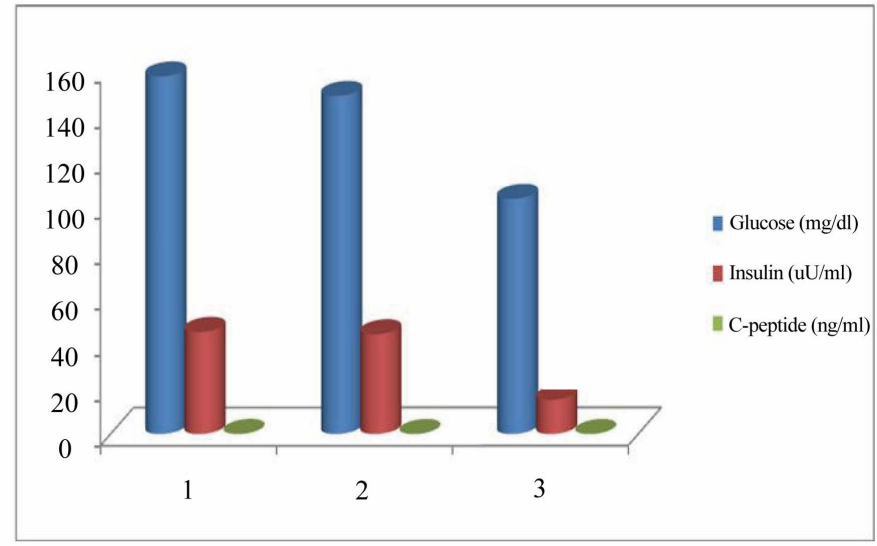

1

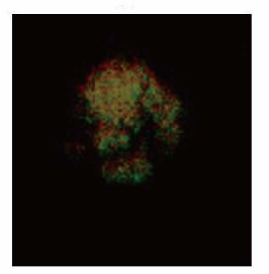

2

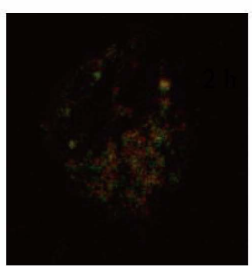

(b)

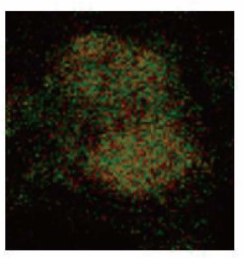


Comprison of Glucose, Insulin and C-peptide concentrations in diabetic patients with confocal representation of their Insulin and LDL receptors

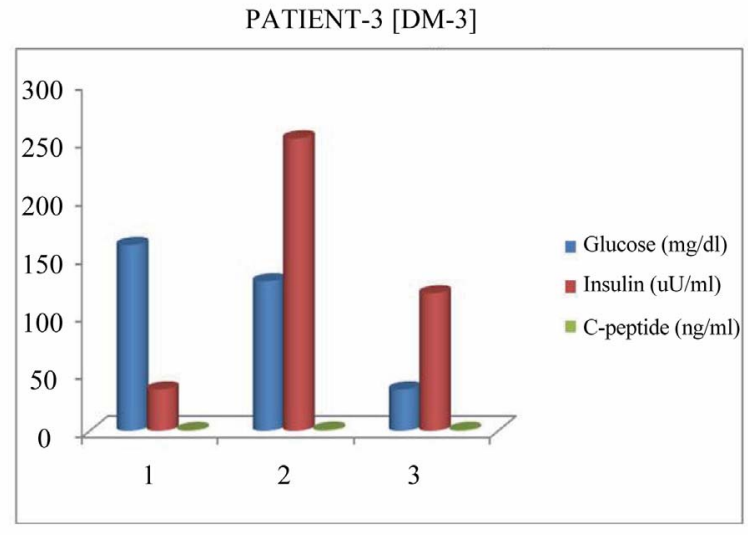

1

3
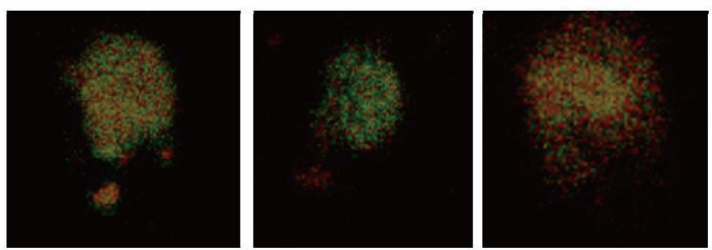

(c)

Biochemical parameters

\begin{tabular}{|l|l|l|l|}
\hline PARAMETERS ( in fasting) & DM-1 & DM-2 & DM-3 \\
\hline PLASMA GLUCOSE (mg/dl) & 236.62 & 157.5 & 160.59 \\
\hline Gly-Hb(\%) & 12 & 9.8 & 16.3 \\
\hline TOTAL CHOLESTEROL (mg/dl) & 166 & 271 & 119.37 \\
\hline LDL-CHOLESTEROL (mg/dl) & 91.35 & 237.9 & 98.63 \\
\hline
\end{tabular}

(d)

Figure 5. The colocalization pattern of two receptors, LDL receptor and insulin receptor, were compared in three diabetic subjects under therapy with their blood glucose, insulin and $\mathrm{C}$-peptide levels in fasting, one hour after insulin injection and immediately before next insulin injection. The biochemical parameters assayed in the fasting blood of those three diabetic subjects are depicted in associated table.

that the diabetic subjects, who were receiving their routine therapy, had higher IR and LDLR expression (Figure 1). But, LDL uptake was significantly lower in the diabetic group (Figure 2). Hence co-localization of IR and LDLR was studied even in more detail from the perspective of insulin activity, in order to suggest a basis for lowered LDLR activity in the diabetic subjects. Since the LDL uptake study was performed on the monocytes isolated from fasting blood samples before any insulin application, the insulin treatment was not expected to have any major influence on the assay system. As Type-I diabetic subjects are in a persistently insulin deficient state, increased co-localization in absent of insulin was taken as indicative of lowered LDLR activity because of the lack of freely available independent LDLRs. 
Co-localization of IR and LDLR was substantiated in THP-1 cells, where IR-LDLR aggregation and its disaggregation in the presence of insulin has also been confirmed by demonstrating co-immunoprecipitation of both receptors (Figure 3(a)). The co-immunoprecipitation was abrogated in presence of insulin.

Confocal microscopy has demonstrated IR-LDLR co-localization (Figure 3(b)), reduced by insulin in cultured PBMCs and THP-1 cells (Figures 3 (c) and (d)). In normoglycemic control subjects, induction of insulin by oral glucose had the same effect; where maximum disaggregation was noted with the peak of insulin level in blood after oral glucose administration (Figure 4). In the diabetic subjects the disaggregation was dependent on externally administered insulin (Figure 5). The absence of any increase in C-peptide level in diabetic subjects was an indicative of the lack of secretion of in vivo biological insulin.

This study suggests that the IR-LDLR co-aggregation in the absence of insulin could be a basis for the reduced LDLR activity in diabetes. It is very well known that two interacting proteins can exist in differential functional states $[35,36]$. Here IR-LDLR is activated by dissociation resulting from interaction of one of the partners with its ligand(s). Although both the receptors can bind their respective ligands simultaneously, other studies in our laboratory (not shown here) have shown the priority of insulin at its level of $15 \mu \mathrm{g} / \mathrm{ml}$ culture medium over LDL in dissociating the two receptors in short interval.

To conclude, we are reporting, to best of our knowledge, for the first time that a large proportion of LDLR and IR interact with each other and are co-localized with each other. This interaction is disrupted by insulin action. There is a suggestion that this interacting LDLR-IR complex has non/less-functional LDLR and could be one of the possible mechanisms for poor LDLR functioning in diabetes.

\section{Acknowledgments}

The confocal microscope facility in the department of physiology, AIIMS, New Delhi, India is gratefully acknowledged. We are greatly thankful to Professor J. Sengupta (for giving access to the confocal microscope facility in the department of physiology) and to Dr. A.K. Dinda (for measuring I.O.D. of immunocytochemistry in his facility in the department of pathology). We greatly appreciate the help from Dr Nandita Gupta, department of endocrinology and metabolism, for the estimation of insulin and c-peptide in our patient's samples. These studies were supported by funding from the Indian Council of Medical Research (ICMR), Government of India; by the Department of Science and Technology
(DST), Government of India; by the Council of Scientific and Industrial Research (CSIR), Government of India and by the Institute Research Grant Support of All India Institute of Medical Sciences (AIIMS), New Delhi, India. The authors thank Prof Subrata Sinha, Head of the department of biochemistry, for editing the manuscript with necessary changes where needed.

\section{REFERENCES}

[1] E. I. Sokolov, "Diabetes Mellitus and Atherosclerosis," Moscow, 1996, p. 404.

[2] P. N. Bodiar, G. M. Denish and O. R. Panasyukova, "Endocrinol Problems," Vol. 3, 1984, pp. 19-24.

[3] A. Araszkiewicz, D. Zozulińska, M. Trepińska, et al., "Inflammatory Markers as Risk Factors for Microangiopathy in Type 1 Diabetic Patients on Functional Intensive Insulin Therapy from the Onset of the Disease," Diabetes Research and Clinical Practice, Vol. 74, No. 2, 2006, pp. S43-S40. doi:10.1016/j.diabres.2006.06.012

[4] S. G. Kozlov and A. A. Lyakishev, "Dyslipoprotenemias and Their Treatment in Patients with Non-Insulin Dependent Diabetes Mellitus," Cardiology, Vol. 39, No. 8, 1999, pp. 59-67.

[5] G. Assmann and H. Schulte, "The Prospective Cardiovascular Munster (PROCAM) Study: Prevelance of Hyperlipidemia in Persons with Hypertension and/or Diabetes Mellitus and the Relationship to Coronary Heart Disease," American Heart Journal, Vol. 116, No. 6, 1988, pp. 1713-1724. doi:10.1016/0002-8703(88)90220-7

[6] M Laakso, "Epidemiology of Diabetic Dyslipidemia," Diabetes Reviews, Vol. 3, 1955, pp. 408-422.

[7] M. Laakso, E. Voutilainen, H. Sarlund, et al., "Serum Lipids and Lipoproteins in Middle-Aged Non-Insulin Dependent Diabetics," Atherosclerosis, Vol. 56, No. 3, 1985, pp. 271-281. doi:10.1016/0021-9150(85)90003-6

[8] K. Pyörälä, M. Laakso and M. Uusitupa, "Diabetes and Atherosclerosis: An Epidemiological View," Diabetes/ Metabolism Reviews, Vol. 3, No. 2, 1987, pp. 463-524. doi:10.1002/dmr.5610030206

[9] G. Steiner, "The Dyslipoproteinemias of Diabetes," Atherosclerosis, Vol. 110, No. S, 1994, pp. 27-33. doi:10.1016/0021-9150(94)05373-Q

[10] M. R. Taskinen, "Quantitative and Qualitative Lipoprotein Abnormalities in Diabetes Mellitus," Diabetes, Vol. 41, No. S2, 1992, pp. 12-17.

[11] S. M. Haffner, M. P. Stern, H. P. Haruda, et al., "Cardiovascular Risk Factors in Confirmed Prediabetic Individuals: Does the Clock for Coronary Heart Disease Start Ticking before the Onset of Clinical Diabetes?" The Journal of the American Medical Association, Vol. 263, No. 21, 1990, pp. 2893-2898 doi:10.1001/jama.263.21.2893

[12] M. Laakso, T. Ronnemaa, K. Pyörälä, et al., "Atherosclerosis Vascular Disease and Its Risk Factors on Non-Insulin Dependent Diabetic and Non-Diabetic Sub- 
jects in Finland," Diabetes Care, Vol. 11, No. 6, 1988, pp. 449-463. doi:10.2337/diacare.11.6.449

[13] J. Stamler, O. Vaccaro, J. D. Neaton, et al., "The Multiple Risk Factor Intervention Trial Research Group. Diabetes and Other Risk Factors on Coronary Heart Disease and Mortality among Middle-Aged Diabetic Men: A General Population Study," Diabetes Care, Vol. 16, No. 2, 1993, pp. 434-444. doi:10.2337/diacare.16.2.434

[14] M. P. Stern, J. K. Patterson, S. M. Haffner, et al., "Lack of Awareness and Treatment of Hyperlipidemia in Type-2 Diabetes in a Community Survey," The Journal of the American Medical Association, Vol. 262, No. 3, 1989, pp. 360-364. doi:10.1001/jama.262.3.360

[15] L. P. Krall, "Clinical Evaluation of Prognosis," In: A. Marble, P. White, R. F. Bradley and L. P. Krall, Eds., Joslin's Diabetes Mellitus, Lea and Febiger, Philadelphia, 1973, pp. 211- 254.

[16] K. Kornerup, B. G. Nordestgaard, B. Feldt-Rasmussen, et al., "Increased Transvascular Low Density Lipoprotein Transport in Insulin Dependent Diabetes: A Mechanistic Model for Development of Atherosclerosis," Atherosclerosis, Vol. 170, No. 1, 2003, pp. 163-168. doi:10.1016/S0021-9150(03)00255-7

[17] D. P. Wade, B. L. Knight and A. K. Soutar, "Regulation of Low-Density-Lipoprotein-Receptor mRNA by Insulin in Human Hepatoma HepG2 Cells," European Journal of Biochemistry, Vol. 181, No. 3, 1989, pp. 727-731. doi:10.1111/j.1432-1033.1989.tb14784.x

[18] G. Ramakrishnan and N. C. Chandra, "Estradiol Regulates Insulin Dependent Stimulation of LDL-Receptor Expression in HepG2 Cells," Indian Journal of Clinical Biochemistry, Vol. 21, No. 1, pp. 8-14.

[19] M. S. Brown and J. L. Goldstein, "A Receptor-Mediated Pathway for Cholesterol Homeostasis," Science, Vol. 232, No. 4746, 1986, pp. 34-47. doi:10.1126/science.3513311

[20] S. Swami, C. Sztalryd and F. B. Kraemer, "Effects of Streptozotocin-Induced Diabetes on Low Density Lipoprotein Receptor Expression in Rat Adipose Tissue," Journal of Lipid Research, Vol. 37, No. 2, 1996, pp. 229-236.

[21] L. Duvillard, F. Galland, E. Florentin, et al., "Cell surface Expression of LDL Receptor is Decreased in Type-2 Diabetic Patients and Is Normalized by Insulin Therapy," Diabetes Care, Vol. 26, No. 5, 2003, pp. 1540-1544. doi:10.2337/diacare.26.5.1540

[22] R. J. Havel, H. A. Eder and J. H. Bragdon, "The Distribution and Chemical Composition of Ultracentrifugally Separated Lipoprotein in Human Serum," Journal of Clinical Investigation, Vol. 34, No. 9, 1955, pp. 13451353. doi:10.1172/JCI103182

[23] G. Ramakrishnan, A. Rana, C. Das and N. C. Chandra, "Study of Low-Density Lipoprotein Receptor Regulation by Oral (Steroid) Contraceptives: Desogestrel, Levonorgestrel and Ethinyl Estradiol in JEG-3 Cell Line and Placental Tissue," Contraception, Vol. 76, No. 4, 2007, pp. 297-305. doi:10.1016/j.contraception.2007.06.011

[24] M. M. Bradford, "A Rapid and Sensitive Method for the
Quantitation of Microgram Quantities of Protein Utilizing the Principle of Protein-Dye Binding," Analytical Biochemistry, Vol. 72, No. 1-2, 1976, pp. 248-254. doi:10.1016/0003-2697(76)90527-3

[25] E. B. Smith and R. S. Slater, "Relationship between Low Density Lipoproteins in Aortic Intima and Serum Lipid Levels," Lancet, Vol. 299, No. 7748, 1972, pp. 463-469. doi:10.1016/S0140-6736(72)90122-5

[26] D. C. Schwenke and T. E. Carew, "Initiation of Atherosclerotic Lesions in Cholesterol-Fed Rabbits, II: Selective Retention of LDL vs. Selective Increases in LDL Permeability in Susceptible Sites of Arteries," Arteriosclerosis, Vol. 9, 1989, No. 6, pp. 908-918. doi:10.1161/01.ATV.9.6.908

[27] M. Cybulsky and M. Gimbrone, "Endothelial Expression of a Mononuclear Adhesion Molecule during Atherogenesis," Science, Vol. 251, No. 4995, 1991, pp. 788-791. doi:10.1126/science. 1990440

[28] K. D. O’Brian, M. D. Allen, T. O. McDonald, et al., "Vascular Cell Adhesion Molecule-1 is Expressed in Human Coronary Atherosclerotic Plaques: Implications for the Mode of Progression of Advanced Coronary Atherosclerosis," Journal Clinical Investigation, Vol. 92, No. 2, 1993, pp. 945-951. doi:10.1172/JCI116670

[29] M. Richardson, S. Hadcock, M. DeReske, et al., "Increased Expression in Vivo of VCAM-1 and E-selectin by the Aortic Endothelium of Normolipidemic and Hyperlipidemic Rabbits," Arteriosclerosis, Thrombosis and Vascular Biology, Vol. 14, No. 5, 1994, pp. 760-769. doi:10.1161/01.ATV.14.5.760

[30] R. G. Gerrity, "The Role of the Monocyte in Atherogenesis, I: Transition of Blood-Borne Monocytes into Foam Cells in Fatty Lesions," American Journal of Pathology, Vol. 103, 1981, pp. 181-190.

[31] R. Ross, "Atherosclerosis Is an Inflammatory Disease". American Heart Journal, Vol. 138, No. 5, 1999, pp. S419-S420. doi:10.1016/S0002-8703(99)70266-8

[32] M. Navab, J. A. Berliner, A. D. Watson, et al., "The Yin and Yang of Oxidation in the Development of the Fatty Streak. A Review Based on the George Lyman Duff Memorial Lecture," Arteriosclerosis, Thrombosis and Vascular Biology, Vol. 16, No. 7, 1994, pp. 831-842. doi:10.1161/01.ATV.16.7.831

[33] P. M. Henson and D. W. H. Riches, "Modulation of Macrophage Maturation by Cytokines and Lipid Mediators: A Potential Role in Resolution of Pulmonary Inflammation," Annals of the New York Academy of Sciences, Vol. 725, 2006, pp. 298-308. doi:10.1111/j.1749-6632.1994.tb39813.x

[34] Y. Liu, L. M. Hulten and O. Wiklund, "Macrophages Isolated from Human Atherosclerotic Plaques Produce IL-8, and Oxysterols May Have a Regulatory Function for IL-8 Production," Arteriosclerosis, Thrombosis and Vascular Biology, Vol. 17, No. 2, 1997, pp. 317-323. doi:10.1161/01.ATV.17.2.317

[35] J. A. Maries, S. Dahesh, J. Haynes, et al., "Protein-Protein Interaction Affinity Plays a Crucial Role in Control- 
ling the Shop-Mediated Signal Transduction Pathway in Yeast," Molecular Cell, Vol. 14, No. 6, 2004, pp. 813823. doi:10.1016/i.molcel.2004.05.024
[36] Y. C. Chen, H. C. Chen and J. M. Yang, “A 3D-Domain Annoted Protein-Protein Interaction Database," Genome Informatics, Vol. 17, No. 2, 2006, pp. 206-215. 